Introduction Recent studies suggest that female workers face a greater risk of long-term chronic disease than male workers. A 2008 Mexican study indicated that older female workers have an elevated prevalence of arthritis, diabetes, and hypertension compared to men. A recent U.S. study showed that women working long hours have an elevated risk for chronic disease later in life compared to men. South Korean researchers reported that women in nonstandard jobs are more likely to suffer chronic mental disorders. However, little is known about why female workers have a comparatively greater risk of long term chronic disease.

Methods This study involves conducting a systematic literature review followed by a meta analysis of studies involving chronic disease among working women, particularly focusing on populations of working women who are aged fifty and older. The review also focuses on identifying distinctive aspects of women's work in specific occupational groups in an international context.

Result Initial results from the analysis suggest several explanations: a) the evidence is relatively strong that working long hours for extended periods of time raises the likelihood for chronic disease, b) the literature suggests that shift work and disruption of circadian rhythms among women can create long-term chronic health problems, c) women are often required to perform multiple roles at home and work which place greater stress on the women's ability to meet those additional responsibilities, d) because of those obligations, many working women may not have sufficient time to take care of their health, and e) some demanding physical tasks might be difficult to perform because of inherent gender-based biological constraints (e.g., performing heavy materials-handling tasks).

Discussion More specific empirical study of the reasons for elevated chronic disease risk among working women is needed. Additionally, workplace-based interventions to screen affected women for chronic disease should be adopted.

\section{THE MEDIATING ROLE OF RECOVERY OPPORTUNITIES ON FUTURE SICKNESS ABSENCE FROM A GENDER- AND AGE-SENSITIVE PERSPECTIVE}

${ }^{1} \mathrm{JS}$ Boschman, ${ }^{2} \mathrm{~A}$ Noor, ${ }^{1} \mathrm{JK}$ Sluiter, ${ }^{2} \mathrm{M}$ Hagberg* ${ }^{*}{ }^{1}$ Academic Medical Centre, University of Amsterdam, Department: Coronel Institute of Occupational Health, Amsterdam Public Health research institute, Amsterdam, The Netherlands; ${ }^{2}$ Occupational and Environmental Medicine, Sahlgrenska Academy and University Hospital, University of Gothenburg, Gothenburg, Sweden

\subsection{6/oemed-2018-ICOHabstracts.1504}

A lack of sufficient recovery during and after work may help to explain impaired health in the long run. We aimed to increase knowledge on the mediating role of recovery opportunities (RO) during and after work on future sickness absence from a gender- and age-sensitive perspective. We used data on RO from a Swedish national survey in 2011 and linked these to sickness absence ( $>14$ days) two years later among the general working population $(n=7,649)$. Mediation of the relationship between gender and sickness absence by exposure to RO was studied through linear regression. We conducted separate analyses for RO during and after work and for three different age groups $(16-29 ; 30-49 ; 50-64)$. The sample consisted of 3563 men and 4086 women. Sickness absence was higher among the women than among the men (11 days vs 5 days, $\mathrm{p}<0.001)$. Men reported statistically significantly more positive on their RO than women. RO during ( $\left.\begin{array}{ll}3 & 0.3-1.8)\end{array}\right)$ and after work ( $B$ 0.4-0.6) mediated the relationship between gender and sickness absence. Mediation effects existed across age groups, with the strongest effects of RO during work found among the age group between 50 and 64 years of age (attenuation 36\%). Our results indicate that gender inequality is also reflected in worse RO among women. This partially explains the increased risk of future sickness absence, particularly among those above 50 years of age. These findings show that RO during work deserve more attention in working life research.

\section{URINARY INCONTINENCE AND INTENTION TO LEAVE CURRENT JOB}

${ }^{1}$ Heather Pierce*, ${ }^{1}$ Lin Perry, ${ }^{2}$ Robyn Gallagher, ${ }^{3}$ Pauline Chiarelli. ${ }^{1}$ University of Technology Sydney, Australia; ${ }^{2}$ Charles Perkins Centre, University of Sydney, Australia; ${ }^{3}$ University of Newcastle, Australia

\subsection{6/oemed-2018-ICOHabstracts. 1505}

Introduction Urinary incontinence (UI) is a condition prevalent in women, with negative impact on pyschosocial health and quality of life. The aim of this study was to examine the relationship between urinary incontinence and work.

Methods An electronic survey was distributed between May 2014 and February 2015 to members of the New South Wales Nurses and Midwives Association in Australia. Urinary incontinence prevalence and severity was investigated using the International Consultation on Incontinence Questionnaire Urinary Incontinence - Short Form. Demographic, general and female reproductive health data known to influence the reporting of UI were collected. Investigated work characteristics included: work role, contract, shift, job satisfaction and plans to leave current job. Data analyses included female respondants and excluded those with a curent pregnancy or urinary tract infection 'sometimes or often' in the last 12 months.

Results The final sample size was 2,907, of mean age 47.35 years (19-74 \pm 11.58$)$; mean Body Mass Index $28.09 \mathrm{~kg} / \mathrm{m} 2$ $(15-57 \pm 6.41) ; 69.9 \%$ were parous. The prevalence of any UI in the past 4 weeks was $32.0 \%$ (95\% CI: $30 \%$ to $34 \%$; $\mathrm{n}=930$ ). Slight severity UI was present in $55.2 \%$, moderate UI in $40.5 \%$ and severe UI in $4.4 \%$. Those with severe UI were more dissatisfied with their work $(\mathrm{p}=0.001)$ and more likely to intend to leave their current position in the next 12 months than those with slight or moderate symptoms (OR: 2.26; 95\% CI: 1.02 to 5.01) after accounting for age, Body Mass Index, parity, anxiety, depression, work contract, shift and job satisfaction.

Conclusion UI is a health concern for women in the workforce, associated with reduced job satisfaction and an intention to leave current job. The findings of this study flag the need to raise the awareness of this common condition in the workplace as UI is a treatable and preventable condition.

\section{GENDER EQUITY IN EDITORIAL BOARDS OF MEDLINE INDEXED OCCUPATIONAL SAFETY \& HEALTH JOURNALS}

${ }^{1}$ Priyanka Roy*, ${ }^{2}$ Soumyadeep Bhaumik. 'Department of Labour, Government of West Bengal, India; ${ }^{2}$ Public Health Foundation of India, India

10.1136/oemed-2018-ICOHabstracts. 1506 
Introduction Gender bias in science is a global issue. Being an editor in a journal is considered to be representation of an individual's reputation and leadership. While gender disparity in editorial board of journals in several specialities, has been studied, but not in Occupational Safety and Health (OSH).

Methods MEDLINE indexed journals were searched in the NLM, USA Catalogue with a search strategy. The list of journals retrieved were reviewed to access whether they were in the domain of OSH.

Information pertaining to editors and their roles was obtained from journal websites in June 2017. At this phase, journals which had no editorial list or did not have full names of editors in their websites were excluded. Any individual whose role which was not designated as editor was excluded from the analyses. Gender was determined by multiple methodologies: inspection of names, gender- specific description, photographs in journal or institutional web pages. All data was validated independently by the two authors and differences sorted by consensus.

Since the study used data available in public domain and no human participants were involved it did not require ethics committee approval.

Results 22 journals were retrieved from the NLM catalogue and 16 of them were finally included with a total of 185 editors. Gender could not be determined by for 11 (5.94\%) editors and there were 56 female (30.27\%) editors and 118 male $(63.78 \%)$ editors. 3 out of $16(18.75 \%)$ Editor-in-Chief, 2 out of $8(25 \%)$ Managing editors and 39 out of 101 (38.61\%) Associate editors were female.

Discussion This is the first study providing data on gender diversity in editorial boards of OSH journals and shows significant gender inequity. Qualitative research to understand the enablers and barriers for women to become editors in $\mathrm{OSH}$ journals is warranted.

\section{INEQUITIES OF WORKING WOMEN IN THE INFORMAL SECTOR: A GLOBAL PERSPECTIVE}

${ }^{1}$ Igor Bello*, ${ }^{2}$ Marcia Bandini*. ${ }^{~}$ Dr. University of Carabobo, Valencia, Venezuela; ${ }^{2}$ President of the Brazilian Association of Occupational Medicine ANAMT, Sao Paulo, Brazil

\subsection{6/oemed-2018-ICOHabstracts.1507}

The aim of this special session Women are majority in the informal work and informal employment, facing socioeconomic inequalities that will be shown during this session.

${ }^{1} \mathrm{~J}$ Rodriguez-Guzman, ${ }^{2} \mathrm{SM}$ Copsey, ${ }^{3} \mathrm{O}$ Solar

${ }^{1}$ Prof. Dr. Regional Advisor on Worker's Health, Pan-American Health Organisation/World Health Organisation PAHO/ WHO, Washington, USA

${ }^{2}$ Ms. European Agency for Safety and Health at Work (EUOSHA), Bilbao, Portugal

${ }^{3}$ Dr. International Labour Office, Geneva, Switzerland

\section{0a PAHO'S REGIONAL EFFORTS TO OVERCOME GENDER INEQUALITIES FOR WORKING WOMEN IN THE AMERICAS}

J Rodriguez Guzman. Regional Advisor on Workers' Health, Dept. Family, Direction of Gender and Life Course FGL, Pan-American Health Organisation
PAHO is committed to promote gender equality in health status and health development through research, policies, and programs which give due attention to gender differences in health and its determinants. To achieve this PAHO's Gender Equality Policy is implemented as a cross-cutting policy. All directions and programs of PAHO implement actions in their respective field of expertise, and actively promote equality between women and men. This policy reflects PAHO's unwavering commitment to the principles of equity, respect for human rights, and the exercise of citizenship, in addition to its determination to actively participate in global efforts to eliminate all forms of gender discrimination. The ultimate goal is to achieve gender equality. PAHO has created Gender Observatories since 2009, as channels for monitoring and tracking public policy, anticipating emerging social developments, and gaining empirical evidence, based on official data, regarding the Status of women, and their inequalities in relation to men.

Despite all the efforts, the balance remains to be unequal because of the conditions under which women join the formal and informal sectors. These determine their opportunities to benefit from social protection in health schemes, access and out-of-pocket expenditures. Although several types of schemes were developed during the last two decades to reform social protection systems, they still have significant differences in access for women and men. Women generally are excluded from social security because most of them are in low-productivity informal sectors, limiting their autonomy and empowerment.

1. Women have fewer opportunities to access contributory health protection systems caused by the limitations of the labour market (segregation, no contracts, salary gaps, lack of social benefits);

2. The unpaid workload of caregivers as a major factor limiting job opportunities (increasing due to NCDs and ageing population);

3. Women's working conditions limit their access to pension and retirement plans with health coverage (Women access much less pension and retirement benefits); and,

4. Women pay more out-of-pocket expenses (higher due to service demand and car for family).

In 2017 World Woman's day, PAHO called for action to overcome barriers to accessing social protection in health in the reforms of social protection systems. Social health protection policies must be based on the right to health, addressing and responding to the specific needs of women's different situations. The following recommendations included: avoiding to linking access to social protection in health schemes to formal employment or contributory schemes; increase and improve health insurance coverage, with equity, efficiency, and sustainability, promoting the elimination of direct payment at the point of access to health services, as well as eliminating additional payments by women due to their reproductive role; offer comprehensive health services for women in basic services schemes (in addition to sexual and reproductive health care); and, develop social policies that address the issue of unpaid care in the home, without perpetuating the role of women as caregivers. It is necessary to seek a fair distribution of labour among the state, the community, the private sector, and households - and within households, between men and women. 